\title{
Client Satisfaction and Quality of Life at Primary Healthcare Clinics and Psychiatric Hospitals in the Eastern Province of Saudi Arabia
}

\author{
Osama A. Al-Jama', Abdel W. Awadalla2 ${ }^{2}$, Hiroko Arikawa ${ }^{3}$ \\ ${ }^{1}$ Ministry of Health, Primary Healthcare Clinics of Eastern Province, Khobar, Saudi Arabia \\ ${ }^{2}$ Department of Psychiatry, College of Medicine, Imam Abdulrahman Bin Faisal University (Formerly University of Dammam), \\ Dammam, Saudi Arabia \\ ${ }^{3}$ Independent Author, Springfield, MO, USA \\ Email: *awadal@yahoo.com
}

How to cite this paper: Al-Jama, O.A., Awadalla, A.W. and Arikawa, H. (2019) Client Satisfaction and Quality of Life at Primary Healthcare Clinics and Psychiatric Hospitals in the Eastern Province of Saudi Arabia. Open Journal of Psychiatry, 9, 1-14. https://doi.org/10.4236/ojpsych.2019.91001

Received: November 18, 2018 Accepted: December 23, 2018 Published: December 26, 2018

Copyright $\odot 2019$ by authors and Scientific Research Publishing Inc. This work is licensed under the Creative Commons Attribution International License (CC BY 4.0).

http://creativecommons.org/licenses/by/4.0/

\begin{abstract}
Over the past few years, greater attention has been paid to the importance of incorporating behavioral health treatment into primary health care (PHC) settings in the Kingdom of Saudi Arabia (KSA). The purpose of the present study was to compare the participants' satisfaction on psychological services and quality of life (QOL) among primary healthcare clinics, psychiatric hospitals and healthy controls. The Arabic version of the World Health Organization Quality of Life-short version (WHOQOL-Bref) and Client Satisfaction Questionnaire (CSQ) were administered to 36 PHC participants, 60 hospital participants, and 63 healthy controls. In all QOL domains, there was no significant difference obtained on participants' QOL between PHC and hospital settings. Except for similar score to PHC participants on overall QOL (OQOL), healthy controls scored higher than the other two groups on four QOL domains and General Health $(\mathrm{GH})$ facet. As for clients' satisfaction, participants under PHC setting reported significantly higher satisfaction compared to hospitals and healthy controls. Hospital participants reported higher client care satisfaction than healthy controls. Improvement in the quality of mental health care such as ease of referrals and detection of undiagnosed mental health conditions could be the cause for higher satisfaction with PHC services. Stigma associated with mental illness creates serious barriers to Saudi patient's access to psychiatric clinics of large hospitals. There is a need for incorporating qualified mental health providers into PHC and educating the general public to become aware of certain beliefs and attitudes that limit access to treatment and prospects for recovery of persons with mental ill-
\end{abstract}


nesses.

\section{Keywords}

Primary Healthcare, Client Satisfaction, Quality of Life, Stigma, Saudi Arabia

\section{Introduction}

Over the past several decades, the Alma Ata declaration issued by the World Health Organization [1] has increasingly expressed the need for primary health care (PHC) to be accessible to all individuals and families living in communities worldwide. The conference listed the promotion of mental health treatments as one of the essential elements of PHC services which will reduce mental illness in a community and enhance patients' coping strategies through proper prevention and treatment [2]. The goal of PHC is to provide fundamental healthcare needs and to offer global access to families and individuals in the community close to where they live and work. It is decentralized and requires the active participation of the community and family [3]. McDaniel, Hargrove, Belar, Schroeder, and Freeman [4] identified several goals that included the development and feasible implementation of treatments within PHC based on population care rather than the more intensive individual client-centered care typical of the specialized mental health setting. Ratzliff et al. [5] view behavioral integration into PHC as essential for enhancing access to care, producing better patient outcomes, reducing health care costs, and perhaps improving patient's awareness of healthcare services.

Much evidence supports the need for integrating psychosocial and behavioral healthcare into PHC. For example, in developed countries, one-third of visits to PHC centers were related to psychosocial and behavioral problems [6], and more than two-thirds of the PHC medical appointments were related to psychosocial concerns [7]. In industrialized North America and Western Europe, $25 \%$ of disability that leads to premature death was accounted for by mental disorders [8]. In a developing country such as Lebanon, an epidemiological survey showed that $17 \%$ of respondents met the criteria for at least one mental disorder within a 12-month period [9] [10]. In the capital city of Riyadh in KSA, 30\% to $40 \%$ of those seen in PHC clinics had mental disorders [11]. Another study in KSA showed that mental health problems are often thought to have religious or somatic causes, making them difficult for mental health practitioners to diagnose and treat [12]. Literature from adjacent African countries supports these findings [13] [14] [15]. Regretfully, it was clear that most of these mental health cases were treated either by PHC medical professionals or by religious/traditional healers [16] [17] [18] and that perhaps less than one-third of patients ever met with a psychologist or other mental health providers [19].

Therefore, integrated psychosocial and behavioral health services into PHC 
settings is essential for providing treatment and diagnosis of patients with mental disorders, designing strategies to prevent mental disorders and ensuring the existence of qualified healthcare practitioners to provide proper psychosocial services and counseling [20]. This integration is expected to result in several advantages such as reduction of stigma [9], family burden associated with mental disorders [21], ease of access to mental health services and treatment [22], early detection and prevention of mental conditions [23], and reduction of chronic recurrent course of mental illness [24]. Furthermore, the integration of psychology into PHC settings could help in predicting new definition, explanation, and concept of PHC in the future of the health-care system structure [25]. For instance, to further their ability to collaborate with medical practitioners, psychologists can offer a biopsychosocial explanation and detection of mental illness to patients and their family caregivers [19]. In view of this, some scholars [26] [27] [28] particularly emphasized the availability and timely access to PHC settings to provide psychological services to at-risk populations, such as underserved rural dwellers, victims of abuse, and those with low socioeconomic status.

A few studies have been conducted on patient's satisfaction in Saudi PHC settings [29] [30]. However, no published studies to date have investigated comparing patients' satisfaction and QOL at PHC settings with that of psychiatric hospitals. Therefore, the primary objective of this study was to compare satisfaction and QOL between two groups of participants who received mental health treatments at PHC setting (group1; G1) and psychiatric hospitals (group 2; G2), and also to compare the findings to a healthy control group (G3) recruited from general population.

This research study highlighted the important association between the PHC organizational model and health-related QOL and client satisfaction in persons with mental illness. It was carried out in the Eastern Province (EP) of KSA and hypothesized that participants at PHC would report higher satisfaction and QOL regarding their mental health than participants treated at psychiatric hospitals.

\section{Method}

\subsection{Participants}

Participants from group 1 (G1; PHC attendees) were recruited from three PHC in Dammam and Khobar in KSA. They included 14 males $(M=32.71$ years in age, $S D=5.9)$ and 22 females $(M=32.77$ years in age, $S D=8.21)$ who were regularly receiving mental health services from the clinics.

Group 2 (G2; hospital attendees) participants were recruited from outpatient psychiatric departments at King Fahad University Hospital (KFUH) in Khobar city and Al Amal Complex Hospital (ACH) in Dammam city, KSA. They included 45 males $(M=36.63$ in age, $S D=12.84)$ and 13 females $(M=34.36$ in age, $\mathrm{SD}=10.34)$ who were consecutively receiving mental health services from the hospitals. Two participants did not indicate their gender.

Group 3 (G3; control) served as a healthy control and included 39 males $(\mathrm{M}=$ 
37.47, $\mathrm{SD}=15.14)$ and 24 females $(\mathrm{M}=28.89, \mathrm{SD}=7.55)$ who were recruited from public locations such as schools, universities, lecture halls, supermarkets, and mosques. One participant did not specify his or her gender.

\subsection{Procedure}

Permission was granted to carry out the study from authorities of each clinical setting. The study was conducted in accordance with the Declaration of Helsin$\mathrm{ki}$, and the protocol was approved by the Ethics Committee of General Directorate of Health Affairs (GDHA) in Khobar, EP of KSA. Eligibility criteria included being native Saudi participants of both genders, literate, aged 18 years or older, currently using PHC or psychiatric hospital services and having met the ascertained diagnostic criteria for mental disorders according to the Diagnostic and Statistical Manual of Mental Disorder, $5^{\text {th }}$ ed. (DSM-5) [31].

Participants were consecutive attendees at the PHC and psychiatric hospital settings who fulfilled the study's inclusion criteria. They were approached by the primary investigator (OAA) who used the direct enrollment strategy by approaching each participant individually and asking him or her of whether he or she would be interested in take part in the study. Illiterate or those who were unable to answer questions were excluded. An IRB-approved letter of the study was presented to the treating healthcare providers who assisted in referrals of eligible and interested participants. A considerable care was taken that no participant contacted would feel obliged or pressured to participate. Also, all participants were informed that they had the right to withdraw from the study. Thereafter, OAA visited each facility and handed the measures to each participant after explaining the purpose of the study and confidentiality, responding to their questions effectively and receiving their verbal consent to participate. The questionnaires were completed at the facility while the investigator was waiting in a separate room. Participants returned the anonymously filled questionnaires to the investigator. In addition, healthy control participants were approached in classrooms, supermarkets, and mosques. No identifying information was collected.

\subsection{Measures}

Two assessment instruments were used in the present study: the validated Arabic version of the World Health Organization Quality of Life-short version (WHOQOL-Bref) [32] and the translated Arabic version of the Client Satisfaction Questionnaire (CSQ) [33].

\section{WHOQOL-Bref}

The Arabic WHOQOL-Bref is a 26-item, self-administered questionnaire, a short version of the WHOQOL-100 scale used for assessing participants' subjective responses rather than their objective life conditions [32] [34] [35] [36]. The questionnaire captures four domains of QOL. They are physical health, psychological health, social relations, and environment. The rating uses a five-point 
scale ranging from "dissatisfied" (a score of 1) to "highly satisfied" (a score of 5). The scores are scaled in a positive direction (i.e., higher scores denote higher quality of life) [35]. Individual item ratings are based on transforming raw scores into scores ranging from 4 - 20 to align with WHOQOL-100 instruments [35]. The items are then summed to provide an overall index of satisfaction level [34]. Two additional stand-alone domains that are of particular relevance to an individual's Overall Quality Of Life (OQOL; Q1) and General Health (GH; Q2) facets were assessed separately, as recommended by the WHOQOL Group ([36]. They are used to constitute the general facet of OQOL and health. The test-retest and the internal consistency reliability for the questionnaire and the domains had an acceptable Cronbach's alpha of $\geq 0.7$. Internal consistency reliability on each domain (Cronbach's alpha) was 0.80 for physical health, 0.77 for psychological health, 0.69 for social relations, and 0.83 for environment [32]. Similarly, our current study showed a high reliability for the full questionnaire (alpha $=$ 0.95 ) and adequate to high levels for its four domains: $0.89,0.84,0.84,0.76$, and 0.87 respectively.

\section{Client Satisfaction Questionnaire}

Larsen, Attkisson, Hargreaves and Nguyen ([37] first developed the CSQ, a self-report measure designed to assess the degree of clients' satisfaction with service and elicit their perspective on the value of services received. It is an 8-item measure with rating response options based on a 4-point scale with scores ranging from 1 (quite dissatisfied) to 4 (very satisfied), easily scored by summing the individual item scores to produce a range of 8 to 32, with high scores indicating greater satisfaction [38] [37] 1979). An example of the eight different components that the questionnaire measured is "how satisfied are you with the amount of help you have received?' for which the response options are $1=$ quite dissatisfied, 2 = indifferent or mildly satisfied, 3 = mostly satisfied, and $4=$ very satisfied [39]. Unlike WHOQOL-Bref, CSQ has no subscales and tends to report a single dimension of overall general satisfaction with services [37]. The internal consistency of the original CSQ-8 was high, with Cronbach's alpha coefficients ranging from 0.84 to 0.93 [40]. A similar result of high reliability was reported by the present study (alpha $=0.89$ ). The questionnaire has been translated into different languages, including Arabic [33], and has been used in a wide spectrum of clinical and human services, educational and governmental programs, legal and police services, and administrative and research settings [41] [42] [43] [44] [45].

\subsection{Data Analysis}

PSPP statistical software version 0.10.2 [46] was used for the data analysis. Means, standard deviations and frequency data were calculated to describe participants' sociodemographic and clinical information in each group. Comparisons among the three groups for each of four domains and two facets of WHOQOL-BREF were done using one-way ANOVA, followed by post hoc t-tests with Bonferroni corrections. Similarly, One-way ANOVA was used to compare CSQ scores among 
three groups with post hoc t-tests.

\section{Results}

Table 1 shows the characteristics of the study population. The study had the total of 160 participants $(n=96 ; 60 \%)$ and controls $(n=64 ; 40 \%)$. Participants aged between 18 and 79 years, with the majority (73.9\%) of them young adult native Saudis aged between 18 and 40 years. They were predominantly married

Table 1. Sociodemographic and clinical characteristics of participants and control group $(\mathrm{N}=160)$.

\begin{tabular}{|c|c|c|c|}
\hline & Participants (G1 \& G2) & control (G3) & Total \\
\hline Variables & $\mathrm{N}=96(\%)$ & $\mathrm{N}=64(\%)$ & $N=160$ \\
\hline \multicolumn{4}{|l|}{ Gender } \\
\hline Male & $59(61.5)$ & $39(61.9)$ & \\
\hline Female & $35(36.5)$ & $24(38.1)$ & \\
\hline Mean age for all & $34.11(9.32)$ & $34.4(13.5)$ & \\
\hline \multicolumn{4}{|l|}{ Age group } \\
\hline $18-25$ & $13(14.7)$ & $18 \quad(33.96)$ & \\
\hline $26-40$ & $53(59.2)$ & $16 \quad(35.85)$ & \\
\hline $41-79$ & $30(26.1)$ & $16 \quad(30.19)$ & \\
\hline \multicolumn{4}{|l|}{ Education } \\
\hline Primary/intermed & $10(10.4)$ & $2(3.2)$ & \\
\hline High school & $41(42.7)$ & $15(23.4)$ & \\
\hline College & $45(46.9)$ & $46(71.9)$ & \\
\hline \multicolumn{4}{|l|}{ Occupation } \\
\hline Unemployed /housewife & $26(28.3)$ & $2(3.1)$ & \\
\hline Student & $9 \quad(9.8)$ & $18(28.1)$ & \\
\hline \multicolumn{4}{|l|}{ Employed: } \\
\hline Professionals (e.g., doctor, teacher, eng, etc) & $20(21.3)$ & $28(43.8)$ & \\
\hline Technical (officer, secr, techn) & $20(21.3)$ & $12(18.8)$ & \\
\hline Retired & $10(10.9)$ & $4(6.3)$ & \\
\hline Unspecified & $7(7.6)$ & & \\
\hline \multicolumn{4}{|l|}{ Marital Status } \\
\hline Single & $28(29.2)$ & $18(28.1)$ & \\
\hline Married & $59(61.5)$ & $41(64.1)$ & \\
\hline Divorced/separated/widow & $9(4.7)$ & $4(2.4)$ & \\
\hline \multicolumn{4}{|l|}{ Have a disease } \\
\hline Yes & $35(42.7)$ & $19(32.2)$ & \\
\hline No & $47(57.3)$ & $40(67.8)$ & \\
\hline
\end{tabular}


(61.5\%), educated at a high school or college level (89.6\%), employed at a professional or technical level (42.4\%) and more than one-third (42.7\%) had a history of comorbid disorder. Likewise, majority of healthy controls were young adults between 18 and 40 years (69.8\%), predominantly married (64.1\%), educated at a high school or college level (95.3\%), employed (62.6\%) and nearly one-third (32.2\%) had reported having a disease.

Table 2 shows the means and standard deviations of WHOQOL-BREF scores of participants in G1, G2 and G3. One-way ANOVAs found significant differences among three groups in each domain and overall QOL scores. Post hoc comparisons of groups on each domain were calculated with Bonferroni corrections. The results of the multiple comparison tests showed no significant differences on the QOL level between G1 and G2 across all four domains and General Health (GH) whereas participants in G3 reported significantly higher QOL than G1 and G2 in all domains and GH. The only significant result for overall QOL is that G3 scored significantly higher than G2. There was no difference between G1 and G2, nor was there between G1 and G3 on overall QOL.

Table 3 shows a One-Way ANOVA on CSQ scores which showed significant difference across groups, $F(2,157)=9.45, \mathrm{p}<0.01$. The post hoc analyses indicated that participants in G1 reported significantly higher satisfaction than $\mathrm{G} 2$ ( $t$ $=2.38, p<0.019)$ and G3 $(t=4.55, p<0.01)$. G2 participants reported significantly higher client satisfaction than participants in G3 $(t=2.05, \mathrm{P}<0.042)$.

Table 2. WHOQOL-BREF means and standard deviations across settings.

\begin{tabular}{|c|c|c|c|c|c|}
\hline \multirow{2}{*}{ Domain } & \multicolumn{3}{|c|}{ Settings } & \multirow{2}{*}{$\underline{F}$} & \multirow{2}{*}{$\underline{\mathrm{df}}$} \\
\hline & $\underline{\mathrm{PHC}(\mathrm{G} 1)}$ & $\underline{\text { Hospital (G2) }}$ & Control (G3) & & \\
\hline Physical Health & $13.41(3.25)$ & $14.1(3.49)$ & $15.67(2.29)$ & $7.66^{* *}$ & 2,157 \\
\hline Psychological Health & $13.04(3.27)$ & $13.63(3.47)$ & $15.69(2.73)$ & $10.46^{* * *}$ & 2,157 \\
\hline Social Relationships & $12.96(4.0)$ & $13.08(4.1)$ & $15.96(3.24)$ & $13.55^{\star * *}$ & 2,157 \\
\hline Environment & $13.69(3.14)$ & $13.33(3.46)$ & $15.42(2.64)$ & $7.86^{* *}$ & 2,157 \\
\hline Overall QOL & $3.81(0.95)$ & $3.73(1.06)$ & $4.91(0.69)$ & $4.40^{*}$ & 2,157 \\
\hline General Health & $3.61(0.93$ & $3.60(1.12)$ & $4.13(0.72)$ & $5.93^{\star *}$ & 2,157 \\
\hline $\mathrm{N}$ & 36 & 60 & 64 & & \\
\hline
\end{tabular}

Note. ${ }^{\star}=p<0.05,{ }^{* *}=p<0.01,{ }^{* *}=p<0.001$ Standard deviations appear in parentheses after means.

Table 3. CSQ means and standard deviations across settings.

\begin{tabular}{|c|c|c|c|c|c|}
\hline & \multicolumn{3}{|c|}{ Settings } & \multirow{2}{*}{$\underline{F}$} & \multirow{2}{*}{$\underline{\mathrm{df}}$} \\
\hline & PHC & Hospital & Control & & \\
\hline Mean (sd) & $27.81(4.46)$ & $25.90(4.83)$ & $24.47(4.34)$ & $9.45^{\star *}$ & 2,157 \\
\hline $\mathrm{N}$ & 36 & 60 & 64 & & \\
\hline
\end{tabular}

Note. ${ }^{* *}=p<0.001$. 


\section{Discussion}

This study was conducted in one of the 13 provinces of KSA with the aim to compare mental health participants' reported levels of satisfaction and QOL in mental healthcare between PHC and hospital settings. It used validated Arabic instruments to assess the participants' ratings of their own subjective experiences, which proved to be more accurate measures than clinicians' ratings [47]. It also incorporated a healthy control group recruited from corresponding communities for comparative rating. However, the study was limited by its small sample size which may have reduced power to detect meaningful differences among the groups. Also, the study population was sampled from an urban province (i.e.; EP) that hosts large universities and hospitals, thus the findings cannot be extrapolated to the Saudi rural areas. Future research using more diverse and larger groups of mental patients is needed to establish whether the differences reported herein can be further generalized to other Saudi PHC settings. Despite such limitations, the present findings were in accordance with previous studies [48] that urbanized countries with a well-established PHC system showed significant results in favor of PHC program over hospitals.

The results did not show significant differences in participants' QOL in all four domains and GH between PHC and hospital settings. As expected, the healthy control population reported significantly higher QOL than participants in both settings, as seen in other studies [49]. With regard to participants' satisfaction, the results showed that participants at PHC settings were significantly satisfied compared to participants seen at the hospital settings and among controls. Some possible explanations for higher satisfaction reported by Alshammari [50] included patients' exhibiting less severe diagnoses, quality of clinicians and empathic communication. Prior studies have pointed to these explanations as strongly correlated to patient's satisfaction with favorable outcomes [19] [51]. The higher level of satisfaction shown by the study among hospital group more than control group may be influenced by the new changes and recent advances in Saudi mental health system adopted from WHO [3] quality rights and aimed at promoting quality of mental care such as ease of referrals to mental or general hospitals and improvement in detection of undiagnosed mental conditions [12].

Certain factors could possibly explain poor overall QOL in our clinical sample. Physical and psychological variables such as comorbidities, distressed mood, and lack of occasional assistance in self-care in clinical population have been found to be significantly associated with poor QOL [52] [53]. For instance, Fu et al. [54] reported comorbidities as negatively associated with QOL of chronically ill survivors whereas lower severity in terms of having fewer co-morbid conditions was associated with higher QOL [55]. Our study showed that more than one-third $(42.7 \%)$ of participants had a history of comorbid disorder. Hence, further research considering the combined influence of comorbidity and mental illness on participants' QOL is needed. When investigating Saudi conservative society, still, it is important to mention the fear of confidentiality breaches and 
feelings of guilt and shame arising from social stigma of seeking mental health services [56]. To reduce such ingrained fears, integrated behavioral services within PHC can provide the needed confidentiality for people who require mental healthcare. Literature showed that mental health culture strictly values confidentiality as opposed to medical culture that is organized around referrals and consultation with others [19]. Hence, the patients' bill of rights (PBR) publicized by the Saudi Ministry of Health $(\mathrm{MOH})$ [57] has led to a stronger call for providing an insight into awareness and knowledge of patient's rights such as right to confidentiality and privacy [58]. To reduce stigma, Angantyer et al. [6] perceived brief therapy at PHC as less stigmatizing for clients, especially when it is conducted by a qualified psychotherapist [59]. Other programs to fight against negative attitudes and beliefs about mental illness can be implemented via public awareness campaigns, media messages targeting documented stigma and discrimination [60], and well trained psychologists who have knowledge of PHC strategies and all techniques important for providing effective psychotherapy [19].

While there has been remarkable progress in Saudi mental health system and the number of psychologists is rising [12], PHC system still lacks a well-established program based on psychosocial intervention and precise detection of mental health problems by PHC providers [61] [62]. The present findings encourage the primary care community to put more effort into improving mental illness detection by qualified clinicians in KSA, pay attention to mental conditions that might be manifested by or mixed with medical conditions [12], use routine self-reporting instruments by PHC service providers to accurately assess patient's mental status [63] [64] [65] and make referrals to mental health professionals accessible. Furthermore, programs are necessary to develop a system to keep pace with global improvement of mental health services. Such a change requires mental health professionals' willingness to take an active stance in the movement. Larger scale studies in various provinces are recommended. Also, other variables such as influence of comorbidity, psychiatric diagnoses, client support system in preventing relapse, and skills and experiences of clinicians should be evaluated in future studies.

\section{Acknowledgements}

We are grateful to the authorities at $\mathrm{KFUH}$ and $\mathrm{ACH}$ in Khobar and Dammam for their valuable assistance in consenting to and facilitating data collection. Our thanks also go to the participants for their valuable cooperation and contributions to our study.

\section{Declaration of Authorship}

OAA initiated the idea of the study and collected the data. AWA supervised the study and contributed to data interpretation. HA analyzed and interpreted the data. All authors contributed equally to writing the manuscript, and all read and 
approved the final manuscript.

\section{Conflicts of Interest}

The authors declare that they have no competing interests.

\section{References}

[1] World Health Organization (1978) Declaration of Alma-Ata: International Conference on Primary Health Care, Alma-Ata, USSR, Sep 6-12. World Health Organization, Geneva.

[2] Sartorius, N. (2008) Mental Health and Primary Health Care. Mental Health in Family Medicine, 5, 75-77.

[3] World Health Organization (2001) Mental Health: New Understanding, New Hope. World Health Organization, Geneva. http://apps.who.int/iris/bitstream/10665/42390/1/WHR_2001.pdf

[4] McDaniel, S.H., Hargrove, D.S., Belar, C.D., Schroeder, C. and Freeman, E.L. (2004) Recommendations for Education and Training in Primary Care Psychology. In: Frank, R.G., McDaniel, S. H., Bray, J.H. and Heldring, M., Eds., Primary Care Psychology, APA Books, Washington DC, 63-92. https://doi.org/10.1037/10651-004

[5] Ratzliff, A., Phillips, K.E., Sugarman, J.R., Unützer, J. and Wagner, E.H. (2017) Practical Approaches for Achieving Integrated Behavioral Health Care in Primary Care Settings. American Journal of Medical Quality, 32, 117-121. https://doi.org/10.1177/1062860615618783

[6] Angantyr, K., Rimner, A. and Norden, T. (2015) Primary Care Behavioral Health Model: Perspectives of Outcome, Client Satisfaction and Gender. Social Behavior and Personality, 43, 287-302. https://doi.org/10.2224/sbp.2015.43.2.287

[7] Bryan, C., Morrow, C. and Kanzler-Appolonio, K. (2009) Impact of Behavioral Health Consultant Interventionson Patient Symptoms and Functioning in an Integrated Family Medicine Clinic. Journal of Clinical Psychology, 65, 281-293. https://doi.org/10.1002/jclp.20539

[8] World Health Organization (2001) Atlas. Mental Health Resources in the World. WHO, Geneva.

[9] Hijazi, Z., Weissbecker, I. and Chammay, R. (2011) The Integration of Mental Health into Primary Health Care in Lebanon. Intervention, 9, 265-278.

[10] Karam, E.G., Mneimneh, Z.N., Dimassi, H., Fayyad, J.A., Karam, A.N., Nasser, S. C., et al. (2006) Prevalence and Treatment of Mental Disorders in Lebanon: A National Epidemiological Survey. Lancet, 367, 1000-1006. https://doi.org/10.1016/S0140-6736(06)68427-4

[11] Al-Khathami, A.D. and Ogbeide, D.O. (2002) Prevalence of Mental Illness among Saudi Adult Primary-Carepatients in Central Saudi Arabia. Saudi Medical Journal, 23, 721-724.

[12] Koenig, H.G., Al Zaben, F., Sehlo M.G., Khalifa, D.A., Al Ahwal, M.S., Qureshi, N.A. and Al-Habeeb, A.A. (2014) Mental Healthcare in Saudi Arabia: Past, Present and Future. Open Journal of Psychiatry, 4, 113-130. https://doi.org/10.4236/ojpsych.2014.42016

[13] Ali, S.H. and Agyapong, V.I.O. (2016) Barriers to Mental Health Service Utilization in Sudan-Perspectives of Carers and Psychiatrists. BMC Health Services Research, 16. https://doi.org/10.1186/s12913-016-1280-2 
[14] Mwape, L., Sikwese, A., Kapungwe, A., Mwanza, J., Flisher, A., Lund, C. and Cooper, S. (2010) Integrating Mental Health into Primary Health Care in Zambia: A Care Provider's Perspective. International Journal of Mental Health Systems, 4. http://www.ijmhs.com/content/4/1/21 https://doi.org/10.1186/1752-4458-4-21

[15] Gureje, O. and Alem, A. (2000) Mental Health Policy Development in Africa. Bulletin of the World Health Organization, 78, 475-482.

[16] Stein, M.B., Roy-Byrne, P.P., Craske, M.G., Campbell-Sills, L., Lang, A.J., Golinelli, D., Sherbourne, C.D., et al. (2011) Quality of and Patient Satisfaction with Primary Health Care for Anxiety Disorders. Journal of Clinical Psychiatry, 72, 970-976. https://doi.org/10.4088/JCP.09m05626blu

[17] Wang, P.S., Aguilar-Gaxiola, S., Alonso, J., Angermeyer, M.C., Borges, G., Bromet, E.J., Wells, J.E., et al. (2007) Use of Mental Health Services for Anxiety, Mood, and Substance Disorders in 17 Countries in the WHO World Mental Health Surveys. The Lancet, 370, 841-850. https://doi.org/10.1016/S0140-6736(07)61414-7

[18] Wang, P.S., Lane, M.L., Olfson, M., Pincus, H.A., Wells, K.B. and Kessler, R.C. (2005) Twelve-Month Use of Mental Health Services in the United States: Results from the National Comorbidity Survey Replication. Archive of General Psychiatry, 62, 629-640. https://doi.org/10.1001/archpsyc.62.6.629

[19] Gunn, W.B. and Blount, A. (2009) Primary Care Mental Health: A New Frontier for Psychology. Journal of Clinical Psychology, 65, 235-252. https://doi.org/10.1002/jclp.20499

[20] World Health Organization (2008) Integrating Mental Health into Primary Care: A Global Perspective. World Health Organization, Geneva. http://www.who.int/mental_health/resources/mentalhealth_PHC_2008.pdf

[21] Thornicort, G. and Tansella, M. (2003) What Are the Arguments for Community-Based Mental Health Care? Copenhagen, WHO Regional Office for Europe. Health Evidence Network Report. http://www.euro.who.int/document/E82976.pdf

[22] Hunter, C.L., Goodie, J.L., Oordt, M.S. and Dobmeyer, A.C. (2009) Integrated Behavioral Health in Primary Care: Step-by-Step Guidance for Assessment and Intervention. American Psychological Association, Washington DC.

[23] World Health Organization (2004) Prevention of Mental Disorders: Effective Interventions and Policy Options. World Health Organization, Geneva.

[24] World Health Organization (2007) A Safer Future: Global Public Health Security in the 21st Century. World Health Organization, Geneva. http://www.who.int/whr/2007/whr07_en.pdf

[25] Donaldson, M., Yordy, K. and Vanselow, N. (1994) Defining Primary Care: An Interim Report. National Academies Press (US), Washington DC.

[26] Davis, G.L., Boulger, J.G., Hovland, J.C. and Hoven, N.T. (2007) The Integration of a Telemental Health Service into Rural Primary Medical Care. Journal of Agricultural Safety and Health, 13, 237-246. https://doi.org/10.13031/2013.23349

[27] Jason, L.A., Corradi, K. and Torres-Harding, S. (2005) Preventive Psychology in Primary Health Care Settings. The Journal of Primary Prevention, 26, 37-50. https://doi.org/10.1007/s10935-004-0990-0

[28] Oliveira, J.M., Austin, A.A., Miyamoto, R.E.S., Kaholokula, J.K., Yano, K.B. and Lunasco, T. (2006) The Rural Hawaii Behavioral Health Program: Increasing Access to Primary Care Behavioral Health for Native Hawaiians in Rural Settings. Professional Psychology: Research and Practice, 37, 174-182. 
https://doi.org/10.1037/0735-7028.37.2.174

[29] Al-Moajel, A., Fetohi, E. and Alshammari, A. (2014) Patient Satisfaction with Primary Health Care in Jubail City, Saudi Arabia. World Journal of Medical Sciences, 11, 255-264.

[30] Alfaqeeh, G., Cook, E.J., Rndhawa, G. and Ali, N. (2017) Access and Utilization of Primary Health Care Services Comparing Urban and Rural Areas of Riyadh Providence, Kingdom of Saudi Arabia. BMC Health Services Research, 17, 106. https://doi.org/10.1186/s12913-017-1983-Z

[31] American Psychiatric Association (2013) Diagnostic and Statistical Manual of Mental Disorders. 5th Edition, American Psychiatric Publishing, Arlington. https://doi.org/10.1176/appi.books.9780890425596

[32] Ohaeri, J.U. and Awadalla, A.W. (2009) The Reliability and Validity of the Short Version of the WHO Quality of Life Instrument in an Arab General Population. Annals of Saudi Medicine, 29, 98-104. https://doi.org/10.4103/0256-4947.51790

[33] Attkisson, C.C. (2012) Administering and Scoring the CSQ Scales. http://www.csqscales.com/pdfs/CSQ\%20AdministeringScoring.pdf

[34] Skevinton, S.M., Lotfy, M. and O'Connell, K.A. (2004) The World Health Organization's WHOQOL-BREF Quality of Life Assessment: Psychometric Properties and Results of the International Field Trial. A Report from the WHOQOL Group. Quality of Life Research, 13, 299-310. https://doi.org/10.1023/B:QURE.0000018486.91360.00

[35] WHOQOL Group (1996) WHOQOL-BREF Introduction, Administration, Scoring, and Generic Version of the Assessment: Field Trial Version. World Health Organization, Geneva.

[36] WHOQOL Group (1994) Development of the WHOQOL: Rationale and Current Status. International Journal of Mental Health, 23, 24-56. https://doi.org/10.1080/00207411.1994.11449286

[37] Larsen, D.L., Attkisson, C.C., Hargreaves, W.A. and Nguyen, T.D. (1979) Assessment of Client/Patient Satisfaction: Development of a General Scale. Evaluation and Program Planning, 2, 197-207. https://doi.org/10.1016/0149-7189(79)90094-6

[38] Gani, N., Saeed, K., Minhas, F.A., Anjuman, N., Waleed, M. and Fatima, G. (2011) Assessment of Patient Satisfaction with Mental Health Services in a Tertiary Care Setting. Journal of Ayub Medical College Abbottabad, 23, 43-46.

[39] Nguyen, T.D., Attkisson, C.C. and Stegner, B.L. (1983) Assessment of Patient Satisfaction: Development and Refinement of a Service Evaluation Questionnaire. Evaluation and Program Planning, 6, 299-314. https://doi.org/10.1016/0149-7189(83)90010-1

[40] Gaston, L. and Sabourin, S. (1992) Client Satisfaction and Social Desirability in Psychotherapy. Evaluation and Program Planning, 15, 227-231. https://doi.org/10.1016/0149-7189(92)90085-9

[41] Attkisson, C.C. and Greenfield, T.K. (1996) The Client Satisfaction Questionnaire-8 and the Service Satisfaction Questionnaire-30. In: Maruish, M.E., Ed., The Use of Psychological Testing for Treatment Planning and Outcome Assessment, Lawrence Erlbaum Associates, Hillsdale.

[42] Attkisson, C.C. and Pascoe, G.C. (1983) Patient Satisfaction in Health and Mental Health Services. A Special Issue of Evaluation and Program Planning, 6, 185-418.

[43] Greenfield, T.K. (1983) The Role of Client Satisfaction in Evaluating University Counselling Services. Evaluation and Program Planning, 6, 315-327. 
https://doi.org/10.1016/0149-7189(83)90011-3

[44] Maruish, M.E. (2004) The Use of Psychological Testing for Treatment Planning and Outcomes Assessment. 3rd Edition, Vol. 1, Routledge, New York. https://doi.org/10.4324/9781410610614

[45] Matsubara, C., Green, J., Astorga, L.T., Daya, E.L., Jervoso, H.C., Gonzaga, E.M. and Jimba, M. (2013) Reliability Tests and Validation Tests of the Client Satisfaction Questionnaire (CSQ-8) as an Index of Satisfaction with Childbirth-Related Care among Filipino Women. BMC Pregnancy and Childbirth, 13, 235. https://doi.org/10.1186/1471-2393-13-235

[46] GNU Project (2016) GNU PSPP (Version 0.10.2) [Computer Software]. Free Software Foundation. Boston, MA.

[47] Ahmad, I. and ud Din, S. (2010) Patients' Satisfaction from the Healthcare Services. Gomal Journal of Medical Sciences, 8, 95-97.

[48] Mariolis, A., Mihas, C., Alevizos, A., Mariolis-Sapsakos, T., Marayiannis, K., Papathanasiou, M. and Merkouris, B. (2008) Comparison of Primary Health Care Services between Urban and Rural Settings after the Introduction of the First Urban Health Centre in Vyronas, Greece. BMC Health Services Research, 8, 124. https://doi.org/10.1186/1472-6963-8-124

[49] Izadi-Mazidi, M., Davoudi, I. and Mehrabizadeh, M. (2016) Effect of Group Cognitive-Behavioral Therapy on Health-Related Quality of Life in Females with Premenstrual Syndrome. Iran Journal of Psychiatry and Behavioral Sciences, 10, e4961. https://doi.org/10.17795/ijpbs-4961

[50] Al-Shammari, F. (2014) Patient Satisfaction in Primary Health Care Centers in Hail City, Saudi Arabia. American Journal of Applied Sciences, 11, 1234-1240. https://doi.org/10.3844/ajassp.2014.1234.1240

[51] Powell, R.A., Holloway, F., Lee, J. and Sitzia, J. (2004) Satisfaction Research and the Uncrowned King: Challenges and Future Directions. Journal of Mental Health, 13, 11-20. https://doi.org/10.1080/09638230410001654495

[52] Tang, L., Fritzsche, K., Leonhart, R., Pang, Y., Jinjiang, L., Song, L., Schaefert, R., et al. (2017) Emotional Distress and Dysfunctional Illness Perception Are Associated with Low Mental and Physical Quality of Life in Chinese Breast Cancer Patients. Health Quality of Life Outcome, 15, 231. https://doi.org/10.1186/s12955-017-0803-9

[53] Chui, Y., Kuan, H., Fu, I., Liu, R., Sham, M. and Lau, K. (2009) Factors Associated with Lower Quality of Life among Patients Receiving Palliative Care. Journal of Advanced Nursing, 65, 1860-1871. https://doi.org/10.1111/j.1365-2648.2009.05051.x

[54] Fu, M.R., Axelrod, D., Guth, A.A., Cleland, C.M., Ryan, C.E., Weaver, K.R., Melkus, G.D., et al. (2015) Comorbidities and Quality of Life among Breast Cancer Survivors: A Prospective Study. Journal of Personalized Medicine, 5, 229-242. https://doi.org/10.3390/jpm5030229

[55] Feldman, D., Lévesque, J., Lemieux, V., Tourigny, A., Lavoie, J. and Tousignant, P. (2012) Primary Health Care Organization and Quality of Life Outcomes for Persons with Chronic Diseases. Healthcare Policy, 7, 59-72.

[56] Farooqi, Y.N. (2006) Traditional Healing Practices Sought by Muslim Psychiatric Patients in Lahore, Pakistan. International Journal of Disability, Development and Education, 53, 401-415. https://doi.org/10.1080/10349120601008530

[57] Ministry of Health, Saudi Arabia (2011) Patient's Bill of Rights and Responsibilities. http://www.moh.gov.sa/en/HealthAwareness/EducationalContent/HealthTips/Page s/Tips-2011-1-29-001.aspx 
[58] Halawany, H.S., Al-Towiher, O.S., Al-Manea, J.T., Abraham, N.B., Jacob, V. and Al-Maflehi, N. (2016) Awareness, Availability and Perception of Implementation of Patients' Rights in Riyadh, Saudi Arabia. The Saudi Journal for Dental Research, 7, 132-137. https://doi.org/10.1016/j.sjdr.2016.04.003

[59] Auxier, A., Farely, T. and Seiferet, K. (2011) Establishing an Integrated Care Practice in a Community Health Center. Professional Psychology: Research and Practice, 42, 391-397. https://doi.org/10.1037/a0024982

[60] McCracken, K., Carpenter, M. and Fabre, M. (2008) Mental Health, the Media and Public Perceptions: Findings of Exploratory Focus Groups. http://www.docin.com/p-453604663.html

[61] Qureshi, N.A., Al-Habeeb, A.A. and Koenig, H.G. (2013) Mental Health System in Saudi Arabia: An Overview. Neuropsychiatric Disease and Treatment, 9, 1121-1135. https://doi.org/10.2147/NDT.S48782

[62] Ahmed, H.A. (2013) Obstacles Facing Primary Healthcare Physicians in Diagnosing and Managing Depressed Patients in Tabuk Area of Saudi Arabia. Middle East Journal of Family Medicine, 11, 4-9. https://doi.org/10.5742/MEJFM.2013.112209

[63] Ariyo, A.A., Haan, M., Tangen, C.M., Rutledge, J.C., Cushman, M., Dobs, A. and Furberg, C.D. (2000) Depressive Symptoms and Risks of Coronary Heart Disease and Mortality in Elderly Americans. Circulation, Open Journal of Psychiatry, 102, 1773-1779. https://doi.org/10.1161/01.CIR.102.15.1773

[64] Pollard, A., Margolis, R., Niemiec, R., Sals, J. and Aatre, G. (2013) Psychometric Properties of the Primary Carebehavioral Health Screen. Journal of Clinical Psychology in Medical Settings, 20, 302-310.

https://doi.org/10.1007/s10880-012-9355-7

[65] Spitzer, R., Kroenke, K. and Williams, J. (1999) Validation and Utility of a Self-Report Version of PRIME-MD: The PHQ Primary Care Study. Journal of the American Medical Association, 282, 1737-1744. https://doi.org/10.1001/jama.282.18.1737 